\title{
Missing the Poor, Big Time: \\ A Critical Assessment of the Consumer Pyramids Household Survey
}

\author{
Anmol Somanchi ${ }^{\dagger}$
}

August 11, 2021

\begin{abstract}
India's statistical system is in bad shape with a near absence of regular publicly funded household surveys in recent years. All eyes have now turned to the Consumer Pyramids Household Survey (CPHS), a panel survey of over 170,000 households, privately executed by the Centre for Monitoring Indian Economy (CMIE) since 2014. Given its breadth and high frequency, CPHS has become a widely referenced barometer of the Indan economy. Research papers using CPHS have also mushroomed. However, there has been little validation of the nature and quality of CPHS data. Most crucially, is it true that CPHS is an "all-India representative survey" as claimed by CMIE and echoed by multiple articles in prestigious journals? Comparing CPHS with various national surveys on a set of key demographic and economic indicators, this paper argues that, far from being nationally representative, CPHS under-represents women and young children, overrepresents well-educated households and under-represents the poor. A possible source for these biases (among others) is the strange, unorthodox sampling design adopted by CMIE, which differs from standard sampling approaches on various counts. Further, the bias in the CPHS sample appears to be growing in recent years, posing a serious challenge when using the data to study trends over time.
\end{abstract}

\footnotetext{
${ }^{+}$Paris School of Economics (anmol.smnch@protonmail.com). This paper is an extension of earlier work with Jean Drèze (Drèze and Somanchi, 2021b,c). I am grateful to Jean Drèze, Aashish Gupta, Nidhaanjit Jain, and Doug Johnson for detailed comments on an earlier draft, Sanjay Kumar and Shreyas Sardesai for graciously sharing Lokniti-CSDS data tabulations, S. Subramanian for providing clarifications pertaining to NSSO's 2017-18 consumption expenditure survey, and Advait Rajagopal Aiyer, Rosa Abraham, Ishan Anand, Amit Basole, Antara Chakrabarti, Mrinalini Jha, N. Raghunathan, R. Ramakumar and Abhishek Shaw for helpful discussions and suggestions.
} 


\section{Missing the Poor, Big Time: A Critical Assessment of the Consumer Pyramids Household Survey}

In a country like India with a large informal sector and a tiny share of taxpayers, living standards of the poor and marginalized are not adequately reflected in official statistics, enterprise records, tax data, or macroeconomic aggregates. As a result, publicly funded nationally representative surveys have, for many years now, been the main source for reliably understanding the socio-economic conditions of the population. India's national statistical system has been a role model for low- and middle-income countries for its regular representative national household surveys on a range of insightful issues. This has, however, changed in recent years with crucial surveys remaining unavailable for long durations. While the first three rounds of the National Family Health Survey (NFHS) were conducted every six to seven years starting 1992-93, there was an extended gap of a decade between the third round in 2005-06 and the fourth round in 2015-16. More recently, the Household Consumption Expenditure Survey (CES), conducted by the National Sample Survey Organization (NSSO), has met with a similar fate. For many years, 'thick' rounds of CES were conducted every five or six years and smaller 'thin' rounds as often as annually for some periods. Data from these surveys became the bedrock for studying a range of crucial policy issues like poverty, inequality, and nutrition, to only name a few. However, the latest year of publicly available CES data is now nearly a decade old (2011-12). NSSO did conduct a thick CES round in 2017-18 and even prepared a draft report, both of which were suppressed by the government and remain unavailable at the time of writing. ${ }^{1}$

In this statistical vacuum, all eyes have turned to the Centre for Monitoring Indian Economy (CMIE) and its Consumer Pyramids Household Survey (CPHS). CMIE is a private agency engaged in the collection and compilation of Indian statistics, for sale. The CPHS is a periodic survey, conducted thrice a year in successive four-month 'waves' since January 2014. It is based on "an all-India representative sample of over 170,000 households" according to CMIE's website. Further, this is meant to be a panel dataset, largely tracking the same households over time, though response rates vary and new households are frequently added to compensate for attrition.

The country owes a handsome debt to CMIE for coming to the rescue of its battered statistical system. Except for its hefty price, the CPHS dataset is, or at least sounds like, a researcher's dream. It has become a widely referenced barometer of the Indian economy, closely watched for data on income, expenditure, and employment in par-

\footnotetext{
${ }^{1}$ In March 2019, on the heels of the government's decision to suppress the data, 108 economists and social scientists signed an 'open letter' strongly urging the government to "... restore access and integrity to public statistics" (Wire Staff, 2019). Their plea, unfortunately, was to no avail.
} 
ticular. Research papers based on CPHS data are also mushrooming. However, there has been little independent validation of the nature and quality of the CPHS data. Most crucially, is it true that CPHS is a "robust, nationally representative and panel survey of households", as a recent World Bank discussion paper (Bhattacharya and Roy, 2021) puts it, echoing similar descriptions of the survey in prestigious journals like the Quarterly Journal of Economics, the Journal of Economic Perspectives, and JAMA? ${ }^{2}$

In two recent articles in popular media (Drèze and Somanchi, 2021b,c), Jean Drèze and I raised doubts over the representativeness of CPHS and made the case that it likely underrepresents less-educated and poor households in its sample. Mahesh Vyas, MDCEO of CMIE, responded to our critique with an informative rejoinder (Vyas, 2021), re-asserting that CPHS is indeed an all-India representative survey, but we remain unconvinced. This paper details and expands our case by benchmarking CPHS against various national surveys on a set of key demographic and economic indicators - age distribution, sex ratios, social composition, literacy rates, education levels, ownership of household assets, consumption expenditure and income.

Before proceeding further, a few clarifications are due. First, as far as possible, comparisons between different sources have been made for overlapping time periods. However, in the case of some slow-moving variables, sources a few years apart have also been compared. Second, unit-level data has been appropriately weighted at the householdor individual-level when generating estimates from surveys. ${ }^{3}$ Lastly, the analysis presented here is restricted to the pre-Covid time frame (till end-2019) given the serious issues of comparability with pre- and post-Covid data.

To begin with, a review of the CPHS sampling design will help.

\section{CPHS Sampling Design}

CMIE claims that CPHS is representative not just at the all-India and state levels, but also at the level of rural-urban splits of district groupings within states called homogenous regions (described below). As per the extensive supporting documentation made available by CMIE, the original sample for CPHS was created in 2009 using data

\footnotetext{
${ }^{2}$ See Chowdrow-Reich et al. (2020), Lahiri (2020), and Mohanan et al. (2021) respectively.

${ }^{3}$ The weights used are those provided in the respective data series, without any adjustment. In the case of CPHS, the design weight of an observation is scaled by a non-response factor, both of which are provided by CMIE.
} 
from the 2001 Census and surveying began soon after. ${ }^{4}$ With the release of the 2011 Census data, the sample was revamped in late-2013 with most, though not all, of the households being replaced by new ones. ${ }^{5}$ This revamped sample, part new and part legacy, laid the foundation for the launch of CPHS in its present form in January 2014.

CMIE adopted a multi-stage stratified sampling approach. Within states, districts with similar agroclimatic conditions, urbanization levels, and literacy rates (in that order of importance) were clubbed together to form homogenous regions (HR). HRs were divided into rural and urban strata consisting of all Census 2011 villages and towns respectively. The urban strata were further sub-divided into four sub-strata based on the population of towns: (i) very large $(>2,00,000$ households) (ii) large $(60,000$ $2,00,000$ households) (iii) medium (20,000 - 60,000 households) and (iv) small $(<20,000$ households).

In each HR, villages and towns were selected in the following manner. From the rural stratum, 25-30 villages were chosen via simple random sampling. ${ }^{6}$ From the urban stratum, one town was randomly sampled from each of the four population-based sub-strata (wherever such towns existed, that is). Census 2011 data splits towns into wards which are further sub-divided into census enumeration blocks (CEB). In each sample town, CMIE randomly sampled at least 21 CEBs. ${ }^{7}$

CMIE's method of sampling villages and towns differs from other nationally representative surveys in one key aspect. To account for variation in the population of geographical units in a multi-stage sampling design, surveys like NFHS and CES select villages and towns via a probability-proportional-to-size (PPS) approach. This ensures that, in the first sampling stage, units with larger population (which tend to be fewer in number) have a greater probability of being sampled than units with smaller population. On the other hand, CMIE selects villages via simple random sampling (without accounting for population) and sub-divides towns into four sub-groups based on population size and then randomly samples one from each group. This seems like a strange design, apparently adopted to ensure that the urban sample was "well represented by towns of all sizes" (Vyas, 2020, p. 7). This is a puzzling motivation since a PPS approach is likely to have yielded a sufficiently diverse sample under a more efficient design.

\footnotetext{
${ }^{4}$ The documentation is available on the CPHS website, after creating a free account, under the 'How We Do It' tab.

${ }^{5}$ As per CMIE, this was mainly to account for the proliferation of small towns and the consolidation of some large towns in Census 2011 (Vyas, 2020, p. 1).

${ }^{6}$ The number was increased in 2015 to enhance the coverage of districts and sub-districts (Vyas, 2020, p. 10). While CMIE is fairly transparent in their documentation, such additions seem rather ad-hoc in nature.

${ }^{7}$ In towns with larger population, more than 21 CEBs were sampled.
} 
The troubles, however, do not end there. In fact, they deepen when we look at how CMIE selects households at the ultimate stage of sampling. CMIE has a fixed quota of 16 households to be surveyed in each sample village and CEB. As described in great clarity in their documentation (Vyas, 2020, p. 13-14), in the absence of any household listing, CMIE essentially relies on in-field randomization to sample households, an approach they call 'systematic random sampling'. Except, CMIE's approach is quite likely to yield a biased sample since they begin sampling from the 'main street' or 'central circle' in each village and CEB. The teams of CMIE surveyors enter the main street from one end and select every $n^{\text {th }}$ household, where $n$ is a random number between 5 and 15 , moving to 'inner streets' (or 'outer circles') only if the quota of 16 households is not already exhausted. It is a well known fact that Indian villages are spatially segregated spaces better-off households tend to live closer to the village centre and marginalized groups like Scheduled Castes are often forced to the periphery. ${ }^{8}$ Moreover, even in urban areas, recent research points to the persistence of caste-based segregation as well as the 'peripheralization of the poor'. ${ }^{9}$ Hence, commencing sampling from the main street or village centre is unlikely to result in a representative sample. Yet, Mahesh Vyas in his rejoinder argues that the combination of the sample size requirement, the randomly chosen $n$, and the distribution of households between main and inner streets ensures that "access to inner streets is inevitable" (Vyas, 2021). However, the inevitability of reaching inner streets, which Vyas goes to great lengths to explain, only ensures that inner streets are not entirely left out of the sample. It does not negate the fact that main street households are still bound to be over-represented. ${ }^{10}$ Further, it is not clear how CMIE deals with multiple hamlets within a village. Is it to be understood that the entire sample comes from a single, usually central, hamlet? Or perhaps a hamlet is randomly chosen? Unfortunately, the CMIE documentation is not very helpful in this regard.

It is worth noting that the lack of household listings is not unique to CPHS. Various surveys, both globally as well as in India, are executed under similar constraints and they too adopt variants of a "random walk" to sample households. However, unlike CMIE, most of them take great care to begin sampling from a random point in the village.

\footnotetext{
${ }^{8}$ As Dr. B. R. Ambedkar wrote with characteristic clarity in 'States and Minorities' - "At present, the Hindus live in the village and the Untouchables in the ghettos." (Ambedkar, 1947, p. 49). While things may have improved over the years, caste-based segregation is very much alive, perhaps in more covert ways than the past. See Prasad (2021) for a contemporary account from rural Bihar based on narratives from the past and present combined with village maps drawn by Bhuiyan Dalit women depicting the physical spaces they occupy, the location and quality of resources like water and electricity, and access to land.

${ }^{9}$ See Bharathi et al. (2020) for evidence on spatial segregation in five major cities based on Census 2011 data, and Anand (2006) and Tarlo (2003) for a discussion on the 'peripheralization of the poor' in Mumbai and Delhi respectively.

10 This point is clearly conveyed by simple simulations by Shihas Abdul-Razak, Research Associate at Indian Institute of Management Bangalore, made public via a tweet.
} 
Take the case of the sampling methods developed by the World Health Organization's Expanded Program on Immunization (EPI) to generate reliable estimates of vaccine coverage in areas where up-to-date household listings are not available. In one of the standard variants of the EPI design, enumerators reach the centre of the village and randomly chose a direction by, say, spinning a bottle or a pen. Then they count the total number of households from the village centre till the edge of the village in that direction, from which one household is randomly selected as the starting point (Turner et al., 1996, p. 199). In the Indian context, the Annual Status of Education Report (ASER) surveys conducted by the ASER Centre at Pratham use an approach wherein a village is divided into roughly equally sized segments and an equal number of households are sampled from each of the segments - a variant of what is sometimes called 'compact segment sampling'. ${ }^{11}$ Nonetheless, even these methods have been found to be prone to biases and their robustness has been frequently called into question. ${ }^{12}$ Recent empirical work by researchers at IDinsight suggests that, especially in rural India, publicly available voter rolls (maintained and updated by the Election Commission of India) can provide a useful alternative to in-field randomization techniques at a significantly lower cost than conducting household listings (Joshi et al., 2020).

Another issue with the CPHS sampling design that deserves mention is that it results in a highly urban-skewed sample. In the September-December 2019 wave, there were only 3965 villages in the sample compared to 7920 urban CEBs. ${ }^{13}$ As a result, only $35 \%$ of the 147,319 surveyed households came from rural areas, with similar figures applying to other waves. This urban skew is corrected when we apply weights as urban households get much lower design weights than rural households, resulting in a $67 \%-33 \%$ (weighted) split between rural and urban areas in end-2019. In effect, the weights essentially reverse the unweighted rural-urban shares.

One of the biggest selling points of CPHS is that it is supposed to be a panel dataset, largely tracking the same set of households over time. However, as CMIE's own documentation suggests, households drop out from the sample frequently and are replaced by new households to maintain the overall sample size. Further, on a few occasions, as in 2015 and 2017, CMIE has had to revamp their sample in some areas for a variety of reasons, with the sample only stabilizing by 2019 . By which time, in the $18^{\text {th }}$ wave, one can only find $67 \%$ of the households surveyed in the $1^{\text {st }}$ wave. And if one wants to create a balanced panel between waves 1 and 18, one will be left with only $17 \%$ of wave 1 households. As is well known in the literature, attrition is often non-random and can

\footnotetext{
${ }^{11}$ See (ASER Centre, 2019, p. 266). This approach is considered an improvement over the EPI random walk approach (Turner et al., 1996; Milligan et al., 2004).

12 See Chao et al. (2012), Lemeshow and Robinson (1985), Grais et al. (2007), and others reviewed in Joshi et al. (2020).

${ }^{13}$ Vyas (2020), Table 7.
} 
introduce bias. To make matters worse, CMIE's documentation does not provide much clarity on the how the 'replacement' samples are selected.

In independent work, (Sanyal, 2021) also discusses various elements of the CPHS sampling design and raises serious doubts over the representativeness of the sample, including whether it would even qualify as a probability sample.

\section{Demographics}

With this background on the CPHS sampling design in mind, we can start by looking at how CPHS compares with other surveys on basic demographic indicators like age distribution, sex ratios, and social composition.

\subsection{Age distribution}

Table 1 presents the age-distribution of the Indian population in recent years from four sources: Census 2011, CPHS and two nationally representative surveys - NFHS-4 and the annual Sample Registration System (SRS) surveys. While the distributions from the other three sources are broadly consistent with each other, CPHS clearly stands out. According to Census 2011, 19.9\% of India's population - every fifth person - was below the age of ten. In the SRS, in 2014, this proportion was slightly less, $17.9 \%$. But only $13.6 \%$ of the CPHS weighted sample in end-2014 was in this age range, with most of the exclusion happening in the 0-4 years age group. By end-2019, the share of children under-10 in CPHS was down to just 7.7\%, compared to $16.6 \%$ as per SRS 2018, with significant exclusion in both the 0-4 and 5-9 age groups (see Figure 1).

This deficit of young children in CPHS is compensated by an inflated 40-65-years age group. The latter's share was $27 \%$ as per CPHS 2014, compared to $22.4 \%$ and $21.6 \%$ as per SRS 2014 and Census 2011 respectively. By end-2019, their share in CPHS had risen to $34.1 \%$, up by 7.1 percentage points from end-2014. The corresponding figure from SRS 2018 was only $22.2 \%$. This is a really large difference, of nearly 12 percentage points. These comparisons suggests that the CPHS age distribution is skewed towards older ages and that the skew is getting worse over time. This is a crucial issue especially in light of recent attempts to estimate excess mortality using the CPHS in the context of the Covid-19 pandemic (Anand et al., 2021; Ramachandran and Malani, 2021). Given that age has a strong relationship with mortality, the biased and worsening age distribution in CPHS is likely to bias both mortality levels and trends. 
In addition, as Anand et al. (2021) highlight, while CPHS estimates of age-specific mortality rates for older ages closely track SRS estimates, they are significantly higher for younger ages. Of course, there is the question that which of the two sources are more reliable here. Despite being designed to collect data on vital statistics, there is, unfortunately, a certain degree of opacity surrounding SRS mortality estimates given that the underlying unit-level data has never been made public and the way annual deaths or person-years are estimated is not entirely clear. ${ }^{14}$ Nonetheless, recent research has shown that age-specific mortality rates from SRS more or less track estimates from three different sources: NFHS, the government's Annual Health Survey, and the Civil Registration System (Gupta and Sudharsanan, 2021; Vyas et al., 2021; Gupta and Mani, 2021).

\subsection{Sex ratios}

Table 2 compares sex ratios from Census 2011, NFHs- 4 and CPHS. Here, the official sources, Census 2011 and NFHS-4, are themselves at divergence. For instance, looking at all ages, there were 991 females per 1000 males in 2015-16 as per NFHS- 4 but only 940 females in 2011 as per Census. The two sources are more in line when looking at 0-6-year-old children (916 and 914 females per 1000 males respectively). CPHS estimates from early-2014 are, however, in a league of their own -880 females for all ages and 875 females for the 0-6 age group. While Census and NFHS-4 yield different point estimates, they both report a higher sex ratio in rural areas than urban areas. In contrast, CPHS suggests higher sex ratios in urban areas. Further, the sex ratio of the 0-6 age group fluctuates dramatically across CPHS waves, for instance, rising briefly to 932 females in early 2017 only to drop to 890 by early-2019. It is hard to say whether the Census or NFHS- 4 is more reliable here but, in either case, the evidence suggests that CPHS seriously under-represents women.

\subsection{Social composition}

Moving to social composition, it appears that CPHS marginally over-represents Hindus and under-represents Muslims. Hindus made up $84 \%$ of the CPHS sample in early-2014 but only $80 \%$ of the population as per Census 2011 . On the other hand, Muslims comprised only $10 \%$ of the CPHS sample, compared to $14 \%$ as per the Census. Interestingly, and somewhat surprisingly, CPHS seems to be broadly consistent with the Socio-Economic Caste Census 2011 and NFHS-4 (2015-16) in terms of the share of

\footnotetext{
${ }^{14}$ There is also the issue that standard errors are not clustered, despite using a clustered sampling design.
} 
scheduled caste and scheduled tribe households (roughly 30\%-35\% in rural areas as per the three sources).

\section{Literacy and education levels}

In $2011,75 \%$ of Indian adults (15-49 years) were literate as per the Census. In early 2014 , the literacy rate for the same age group was $81 \%$ as per CPHS. Is it possible that the adult literacy rate increased by 6 percentage points in a span of just over two years? That seems unlikely, but we can pursue this matter further by comparing adult literacy rates from CPHS in end-2015 with NFHS-4 conducted in 2015-16. For both males and females, CPHS estimates are yet again 6 percentage points higher than NFHS- $4 .{ }^{15}$ This suggests that, right from its first wave, CPHS may have been missing some illiterate persons in its sample.

The plot thickens when we track literacy rates for the 15-49 age group across successive waves of CPHS data. From end-2016 onwards, literacy rates began rising rapidly in both rural and urban areas and, by early-2019, adult illiteracy was virtually wiped out (see Figure 2). Are such rapid jumps in literacy rates, for a non-school-going age group, realistic? Mahesh Vyas certainly thinks so. In his rejoinder to our initial critique in the Economic Times, he vaguely argues that 'digitization' could explain these trends. ${ }^{16}$ In the absence of any supporting evidence or careful analysis, the argument is hard to buy.

If literacy rates did increase rapidly in recent years, as CPHS suggests, it should also show up in other national surveys conducted in more recent years. But NSSO's 2017-18 household survey on education suggests that, between 2014 and 2017-18, literacy rates among persons aged 7 years or older increased by just 1.9 percentage points (from $75.8 \%$ to $77.7 \%$ ). ${ }^{17}$ Similarly, comparisons between the fourth and fifth rounds of NFHS, conducted in 2015-16 and 2019-20 respectively, for the 11 states where NFHS-5 is on track, also suggest point to only marginal improvement. Consequently, as Figure 3 highlights, by 2019 , the bias against illiterate individuals in the CPHS sample was embarrassingly large.

Stark contrasts also emerge when we look at education levels instead of literacy rates. In late-2018, as per CPHS, only 2\% of adults (15-49 years) had no formal education. In contrast, the nationally representative Periodic Labor Force Survey (PLFS) 2018-19

\footnotetext{
${ }^{15}$ Among 15-49-year-olds, the literacy rates as per NFHS-4 were $68 \%$ and $84 \%$ for males and females respectively, compared to $74 \%$ and $90 \%$ from CPHS.

16 See also this tweet by CMIE.

${ }^{17}$ See National Statistical Office (2020), Statement 3.3.
} 
pegs it at $17 \%$. The Financial Inclusion Insights (FII) survey, an annual survey covering roughly 45,000 individuals across the country, pegs it at $24 \%$ for 2018 . Further, much like other sources, the FII surveys also suggests little improvement in recent years, pointing to a rapidly growing bias in the CPHS sample over time (see Figure 4).

There is of course no guarantee that the other sources provide more reliable estimates for literacy and education than CPHS. However, all the other sources are broadly in sync with each other. Comparisons of literacy rates for the same age cohort between Census 2011 (15-49-year-olds) and FII 2018 (22-56-year-olds) yield similar results (75\% and 73\% respectively). The same holds true for Census 2011 (11-45-year-olds) and NFHS-4 (15-49-year-olds) for both women and men. ${ }^{18}$ This lends some credibility to these sources. On the other hand, Census 2011 (15-49-year-olds) and CPHS 2019 (2357 -year-olds) comparisons ( $75 \%$ and $93 \%$ respectively) point to a clear overestimation of literacy rates in CPHS.

\section{Ownership of household assets}

If the CPHS sample misses less-educated households, then it is natural to expect that poorer households would be underrepresented. This is indeed the indication we get when looking at ownership of household assets. According to CPHS, for instance, $98 \%$ of households had electricity in late $2015,93 \%$ had water within the house, $89 \%$ had a television and $42 \%$ had a fridge. The corresponding figures from NFHS- 4 are much lower: $88 \%, 67 \%, 66 \%$ and $30 \%$ respectively (Table $3 a$ ).

Similar comparisons can be made between CPHS and NFHS- 5 for 2019 for the 11 states where NFHS- 5 is on track and state reports are available. A serious bias is evident here as well. Take the case of Bihar. According to CPHS, $100 \%$ of households in Bihar had electricity in late $2019,100 \%$ had water within the house, $98 \%$ had a toilet and $95 \%$ had a television. These figures are absurd and beyond belief. The corresponding NFHS-5 figures are much lower, and far more plausible (96\%, 89\%, 62\% and $35 \%$ respectively). Bihar is just one state, but a similar contrast emerges for the 11 states together (Table 3a).

The bias is also clearly evident when comparing CPHS with recent election surveys

${ }^{18}$ Eighty five percent of 11-45-year-old males were literate in 2011 as per the Census; four years later, in 2015-16, the literacy rate among 15-49-year-old males was $86 \%$ as per NFHS-4 (the corresponding figures for females of the same ages were $71 \%$ and $68 \%$ respectively). Similar comparisons for NFHS-5 could not be made since unit-level data has not yet been released and the available state reports present literacy rates for a fixed age cohort. 
conducted by Lokniti at the Centre for Study of Developing Societies (CSDS), New Delhi. According to CPHS, again, in the 11 major states where NFHS-5 is on the track, only $6 \%$ of households did not have a television in 2019 , compared to $26 \%$ and $23 \%$ as per Lokniti-CSDS's National Election Survey (NES) 2019 and State Election Surveys (SES) 2017-21 respectively. ${ }^{19}$ The corresponding figure from NFHS-5 is $29 \%$. As Table $3 \mathrm{~b}$ highlights, estimates of comparable poverty indicators from Lokniti-CSDS's election surveys are relatively easy to reconcile with NFHS- 5 while CPHS estimates are not, they are way off.

\section{Consumption expenditure}

Historically, NSSO surveys have steered clear of recording incomes considering the difficulties in collecting such data, especially for the agricultural sector. Instead, they have focused on recording detailed data on consumption expenditures. In a sense, this has made the NSSO's CES central to gauging the economic conditions of Indian households. As noted earlier, with the suppression of the 2017-18 CES round, there has been no public survey on consumption expenditures since 2011-12. This has significantly enhanced the value-add of CPHS which provides detailed monthly data on both consumption expenditure and incomes. But CMIE only visits households once every four months, i.e. once in each wave of data collection. So how do they provide users with a monthly series for the entire sample? By asking households to report incomes and expenditure for each of the last four months in every visit. As a result, the gap between the reference month and survey month could be as large as 120 days for a quarter of the monthly observations. Moreover, the gap is different for each of the four monthly observations for a household in a wave. ${ }^{20}$

How do CPHS estimates of consumption expenditure compare with other surveys? As it happens, during 2017-18, three national surveys recorded consumption expenditure - CES, CPHS and PLFS. Table 4 presents decile-specific means (in constant January 2017 prices) for rural and urban areas from the three surveys. While not perfectly comparable, CES and CPHS are similar in the sense of detailed recording of expenditure on various individual commodities. On the other hand, PLFS is not geared towards

\footnotetext{
19 The SES were conducted at the state-level and their timing coincided with the assembly elections in the 11 states, starting with Himachal Pradesh in November 2017 and ending with West Bengal and Kerala in March and April 2021.

${ }^{20}$ This is a non-trivial issue since differences in recall periods are known to affect responses (Deaton, 2018). Users of CPHS data are of course free to retain only observations pertaining to the month immediately preceding the survey, as Bhattacharya and Roy (2021) do. But then one is left with 'wave-level' data, not a monthly series.
} 
measuring consumption expenditure and asks a short set of 3-4 questions to ascertain 'usual' consumption expenditure in a month. So let us first focus on CES and CPHS comparisons.

In rural areas, in all but one decile, CPHS estimates are higher than CES and the gap widens as we move up the income distribution. At the fourth and fifth deciles (roughly the middle of the distribution), CPHS estimates are roughly 15\%-20\% higher than CES. The overall CPHS mean exceeds the CES mean by over $25 \%$. In contrast, CPHS appears to underestimate expenditure in urban areas, by roughly $10 \%$ across the distribution. These broad trends are confirmed by Dhingra and Ghatak (2021) who also find overestimation in rural areas (by 10\%) and underestimation in urban areas (by $20 \%$ ), though by slightly different magnitudes. Nonetheless, they report that the all-India poverty head count ratio for 2017-18 from CPHS (25\%) was ten percentage points lower than the estimate from CES by Subramanian (2019a). This suggests that, on aggregate, CPHS misses poor households by a significant margin. It is also worth noting that the two surveys used slightly different recall periods for recording expenditures and it is likely that poverty underestimation in CPHS would be even higher if identical recall periods were used. CPHS uses a "uniform reference period" (URP) with a 30-day recall for all commodities. In contrast, NSSO uses variants of a "mixed reference period" (MRP), with a short (7-day or 30-day) recall for certain commodities including food and a longer (365-day) recall for expenditures on durable goods, health and education (the reported value for which is divided by 12 to arrive at a monthly estimate). Compared to URP, MRP is likely to yield higher expenditure estimates at the lower tail of the distribution, since the longer recall component is more likely to capture expenditures that happen infrequently (Deaton and Kozel, 2005).

Two broad patterns stand out once we bring PLFS into the picture. First, PLFS estimates are lower than CPHS in both rural and urban areas. Second, PLFS estimates are also lower than CES estimates, though the gap gets progressively smaller as we move up the distribution. This is not very surprising given that PLFS records expenditures in a much less detailed manner than the other two surveys. ${ }^{21}$ Interestingly, however, the mean of top two deciles in urban areas from PLFS are marginally higher than the corresponding figures from CPHS (though lower than CES). This suggests that along with its tendency to miss poor households, CPHS may also be missing very rich households, especially in urban areas, as Dhingra and Ghatak (2021) also point to. There are some other hints to this effect as well. For instance, the share of households owning a computer is higher in both NFHS- 4 and NFHS-5 than in CPHS for the corresponding time periods.

${ }^{21}$ It is also worth noting that the issue of differences in recall periods applies to PLFS as well. 


\section{Income}

The only other recent national survey besides CPHS with data on incomes is PLFS. While CPHS records incomes from all sources, both labour and non-labour, PLFS only records labour incomes. It is, however, possible, to compare labor incomes reported in both surveys, as done by researchers at the Centre for Sustainable Employment at Azim Premji University for the year 2018-19. Their estimates, presented in the 'State of Working India 2021' report (Azim Premji University, 2021), suggest that CPHS overestimates average labour income in both rural and urban areas, by $50 \%$ and $13 \%$ respectively (Table 5).

Interestingly, the tenth percentile of the CPHS labour income distribution was zero in both rural and urban areas while the corresponding figures from PLFS were 2630 and 4345 respectively. This may seem contradictory at first. But if we note that these estimates are for individuals, not households, and that labor force participation rates (LFPR) of women and young adults tend to be higher on average among poorer households, then it is easy to see how a sample that underrepresents the poor could have a larger share of 'zero income' individuals than an unbiased sample. Indeed, Abraham et al. (2020, p. 42) report that the women LFPR in 2018-19 was twice as high in PLFS than in CPHS, in both rural and urban areas. Not surprisingly, the income deficit in CPHS vanishes rather quickly - the $25^{\text {th }}$ percentile of CPHS is already higher than PLFS and the gap widens as we move further up the distribution. At the very top, in rural areas, CPHS overestimates labour incomes by nearly two-thirds at the $90^{\text {th }}$ percentile and by nearly $90 \%$ at the $95^{\text {th }}$ percentile.

\section{Discussion}

The evidence presented here clearly shows that, far from being nationally representative, CPHS underrepresents women and young children, overrepresents well-educated households and underrepresents the poor. The results point to a clear pattern of poverty underestimation vis-à-vis other national surveys and suggest that CPHS does not adequately reflect the deprivations of the poor. One possible source for these biases is the strange, unorthodox sampling design adopted by CMIE, which deviates from standard sampling approaches in significant ways. In particular, the CPHS sample is likely to suffer from a 'main street bias' since, in each ultimate sampling unit, CMIE begins interviewing households from the main street and moves to inner streets only to the extent that the sample size demands. What is surprising, however, is that the social composition of the CPHS sample is broadly consistent with other sources. Considering 
the main street bias, one would expect marginalised groups like scheduled castes to be under-represented in the sample. Given that is not the case, there is a need for further scrutiny of other possible sources of biases. The discrepancies observed are so large and puzzling in some cases (95\% of households in the Bihar CPHS sample owning a television in late-2019, compared to just $35 \%$ as per NFHS-5, being just one example) that it is certainly possible for multiple biases to be at play.

One important aspect not dealt with sufficiently here is the 'panel' nature of CPHS data. As noted earlier, there is regular attrition from the CPHS sample and new households are frequently added to maintain sample size. Non-random attrition is a serious possibility. Further, CMIE's method of selecting replacement samples is not clear at all. It would not be surprising if the rapid rise in adult literacy rates and education levels as well as the growing skew in the age distribution in CPHS were at least partly influenced by issues of this sort. In any case, irrespective of the source, the fact that the bias in the CPHS sample appears to be growing in recent years poses a serious challenge when using the data to study trends over time.

Before concluding, a couple of examples may help to illustrate why the representativeness of the CPHS sample is a crucial matter. The absence of official household surveys in India was felt most acutely during the Covid-19 crisis when data on incomes and expenditure were necessary to understand the economic effects of the pandemic and the lockdown. As it happens, however, numerous household surveys, covering mainly the informal sectors of the economy, were conducted by independent research institutions and civil society organisations in 2020. In a recent review of 76 such surveys (Drèze and Somanchi, 2021a), we found that while employment, income, and food security were worst hit during the national lockdown months of April and May 2020, distress likely continued late into the year, well after the lockdown was lifted. ${ }^{22}$ On the other hand, a recent NBER working paper that uses income and expenditure data from CPHS and treats it as a representative survey concludes that "... the economic shock of COVID in India was harsh, but short-lived" (Gupta et al., 2021). However, the trends from CPHS are possibly misleading given the moving bias in the sample.

There are hints that similar concerns may apply when using CPHS to assess the effects of demonetization. Chowdrow-Reich et al. (2020), who use employment data from CPHS (along with night-lights data) to study the economic effects of demonetization, find that while employment did fall initially, the negative effects dissipated soon, in just a matter of a couple of months. Our own analysis of income and consumption data

\footnotetext{
22 See Centre for Sustainable Employment, Azim Premji University (2021), Dhingra and Kondirolli (forthcoming), IDinsight, World Bank and Data Development Lab (2020), Inclusion Economics (2021), among others referenced in the review.
} 
from CPHS also suggests that the demonetization months could almost go unnoticed (see Figure 5). Is it possible these trends were also driven by a bias towards better-off households who were less affected by the currency ban?

Despite the issues raised here, CPHS still has value as a regular national survey covering a broad range of indicators. We have ourselves learnt much from it. It is worth remembering that other national surveys, like NSSO's consumption survey, have benefited immensely from the lively debate and criticism surrounding their methodology, leading to revisions and improvements over time. ${ }^{23}$ Few surveys are ever perfect and less-thanperfect data can still be put to good use when handled cautiously. There may even be ways for researchers to correct some of the observed bias, for instance, by re-weighting CPHS observations to bring the distribution of key indicators in alignment with other sources. Of course, if CMIE is committed to improving the survey methodology in future rounds, as they have assured in response to some of these criticisms, nothing like it.

\footnotetext{
${ }^{23}$ As an example, see Deaton and Kozel (2005) for a review of the evolution of the NSSO consumption surveys and the spirited debate covering various elements of its methodology.
} 


\section{References}

Abraham, R., Basole, A., and Kesar, S. (2020). “Tracking Employment Trajectories In the Covid-19 Pandemic: Evidence from Indian Panel Data". Centre for Sustainable Employment Working Paper 35.

Ambedkar, B. R. (1947). States and Minorities: What are Their Rights and How to Secure Them in the Constitution of Free India. Mumbai: C. Murphy for Thacker \& Co., Ltd.

Anand, A., Sandefur, J., and Subramanian, A. (2021). “Three New Estimates of India's All-Cause Mortality during the Covid-19 Pandemic". CGD Working Paper 589, Washington DC: Center for Global Development.

Anand, N. (2006). "Disconnecting Experience: Making World-Class Roads in Mumbai". Economic and Political Weekly, 41(31):3422-3429.

ASER Centre (2019). Annual Status of Education Report (Rural) 2018 (Provisional). New Delhi: ASER Centre, Pratham.

Azim Premji University (2021). State of Working India 2021: One Year of Covid-19. Bengaluru: Centre for Sustainable Employment, Azim Premji University.

Bharathi, N., Malghan, D., Mishra, S., and Rahman, A. (2020). "Residential segregation in urban India and persistence of caste”. Ideas for India, 1 July.

Bhattacharya, S. and Roy, S. S. (2021). "Intent to Implementation: Tracking India's Social Protection Response to Covid-19". World Bank Social Protection and Jobs Discussion Paper 2107.

Centre for Sustainable Employment, Azim Premji University (2021). "How robust is the recovery? Tracking informal workers through the pandemic". CSE-APU Presentation.

Chao, L., Szrek, H., Peltzer, K., Ramlagan, S., Fleming, P., Leite, R., Magerman, J., Ngwenya, G., Pereira, N., and Behrman, J. (2012). "A comparison of EPI sampling, probability sampling, and compact segment sampling methods for micro and small enterprises". Journal of Development Economics, 98:94-107.

Chowdrow-Reich, G., Gopinath, G., Mishra, P., and Narayanan, A. (2020). "Cash and the Economy: Evidence from India's Demonetization". Quarterly Journal of Economics, 135(1):57-103.

Deaton, A. (2018). The Analysis of Household Surveys: A Microeconometric Approach to Development Policy. Reissue Edition with a New Preface, Washington DC: World Bank. 
Deaton, A. and Kozel, V. (2005). "Data and Dogma: The Great Indian Poverty Debate". The World Bank Research Observer, 20(1):177-199.

Dhingra, S. and Ghatak, M. (2021). "How has Covid-19 affected India's economy?". Economics Observatory, 30 June.

Dhingra, S. and Kondirolli, F. (forthcoming). City of Dreams No More, A Year On: Worklessness and Active Labour Market Policies in Urban India. London: Centre for Economic Performance, London School of Economics.

Drèze, J. P. and Somanchi, A. (2021a). "The Covid-19 Crisis and People's Right to Food". SocArxiv, 31 May.

Drèze, J. P. and Somanchi, A. (2021b). "Not having the have-nots". Economic Times, 21 June.

Drèze, J. P. and Somanchi, A. (2021c). "Bias It Is". Economic Times, 27 June.

Grais, R. F., Rose, A., and Guthmann, J. (2007). “Don't spin the pen: two alternative methods for second-stage sampling in urban cluster surveys". Emerging Themes in Epidemiology, 4(8).

Gupta, A., Malani, A., and Woda, B. (2021). "Explaining the Income and Consumption Effects of Covid in India”. NBER Working Paper 28935.

Gupta, A. and Mani, S. (2021). "Assessing mortality registration in Kerala: The MARANAM Study". SocArxiv.

Gupta, A. and Sudharsanan, N. (2021). "Large and persistent life expectancy disparities among India's social groups". SocArxiv.

IDinsight, World Bank and Data Development Lab (2020). Covid-19 related shocks in rural India: Rounds 1-3. ('Key indicator' data file available here).

Inclusion Economics (2021). Over a year after the first Covid-19 lockdown, migrants remain vulnerable. 28 April, New Haven: Yale Economic Growth Center.

International Institute for Population Sciences (2017). National Family Health Survey (NFHS-4) 2015-16: India. Mumbai: IIPS.

International Institute for Population Sciences (2021). National Family Health Survey (NFHS-5) 2019-20: State Reports. Mumbai: IIPS.

Joshi, R., McManus, J., Nagpal, K., and Fraker, A. (2020). "Are voter rolls suitable sampling frames for household surveys? Evidence from India". IDinsight working paper. 
Lahiri, A. (2020). "The Great Indian Demonetization". Journal of Economic Perspectives, 34(1):55-74.

Lemeshow, S. and Robinson, D. (1985). "Surveys To Measure Programme Coverage And Impact: A Review of the Methodology used by the Expanded Programme on Immunization". World Health Statistics Quarterly, 38:65-75.

Milligan, P., Njie, A., and Bennett, S. (2004). "Comparison of two cluster sampling methods for health surveys in developing countries". International Journal of Epidemiology, 33:469-476.

Mohanan, M., Malani, A., Krishnan, K., and Acharya, A. (2021). "Prevalence of SARSCoV-2 in Karnataka, India". JAMA, 325(10):1001-1003.

National Statistical Office (2020). Household Social Consumption on Education in India. NSS Report No. 585, New Delhi: Ministry of Statistics and Programme Implementation, Government of India.

Office of the Registrar General \& Census Commissioner, India (2011). Census 2011: Provisional Population Totals. Paper 2, Volume 1 of 2011, Rural-Urban Distribution, New Delhi: Government of India.

Prasad, I. (2021). "Caste-ing Space: Mapping the Dynamics of Untouchability in Rural Bihar, India". CASTE: A Global Journal on Social Exclusion, 2(1):132-152.

Ramachandran, S. and Malani, A. (2021). "All-cause mortality during SARS-CoV-2 Pandemic in India: Nationally-representative estimates independent of official death registry". medRxiv.

Sanyal, S. (2021). "Sampling of CPHS - A few observations". Unpublished draft.

Subramanian, S. (2019a). "What is happening to Rural Welfare, Poverty, and Inequality in India?". The India Forum, 29 November.

Subramanian, S. (2019b). "Letting the Data Speak: Consumption Spending, Rural Distress, Urban Slow-Down, and Overall Stagnation". The Hindu Centre for Politics and Public Policy, 11 December.

Tarlo, E. (2003). Unsettling Memories: Narratives of the Emergency in Delhi. New Delhi: Permanent Black.

Turner, A. G., Magnani, R. J., and Shuaib, M. (1996). "A Not Quite as Quick but Much Cleaner Alternative to the Expanded Programme on Immunization (EPI) Cluster Survey Design". International Journal of Epidemiology, 25(1):198-203. 
Vyas, M. (2020). Consumer Pyramids Household Survey: Survey Design and Sample. 12 March, Mumbai: Centre for Monitoring Indian Economy.

Vyas, M. (2021). "Limitations? Sure. But Bias? Nope”. Economic Times, 23 June.

Vyas, S., Hathi, P., and Gupta, A. (2021). "Social disadvantage, economic inequality, and life expectancy in nine Indian states". SocArxiv.

Wire Staff (2019). "108 Economists, Social Scientists Raise Red Flags Over Interference in Data Estimation". The Wire, 14 March. 
Table 1: Age-distribution of the population in recent years

\begin{tabular}{|c|c|c|c|c|c|c|c|c|c|}
\hline \multirow{2}{*}{ Ages } & \multirow{2}{*}{$\frac{2011}{\text { Census }}$} & \multicolumn{2}{|c|}{2014} & \multirow{2}{*}{$\frac{2015-16}{\text { NFHS } 4}$} & \multicolumn{2}{|c|}{2016} & \multicolumn{2}{|c|}{2018} & \multirow{2}{*}{$\begin{array}{l}2019 \\
\text { CPHS }\end{array}$} \\
\hline & & SRS & CPHS & & SRS & CPHS & SRS & CPHS & \\
\hline $0-4$ & 9.4 & 8.9 & 5.0 & 9.1 & 8.5 & 4.4 & 8.0 & 2.8 & 2.3 \\
\hline $5-9$ & 10.5 & 9.0 & 8.6 & 9.5 & 8.9 & 8.0 & 8.6 & 6.3 & 5.4 \\
\hline $10-14$ & 11.0 & 9.7 & 10.3 & 10.1 & 9.6 & 9.9 & 9.3 & 10.3 & 10.2 \\
\hline $15-19$ & 10.0 & 10.1 & 11.1 & 9.4 & 10.1 & 10.9 & 10.2 & 11.1 & 11.6 \\
\hline $20-24$ & 9.2 & 10.3 & 9.7 & 9.0 & 10.4 & 9.5 & 10.8 & 10.0 & 10.1 \\
\hline $25-29$ & 8.4 & 9.5 & 8.4 & 8.4 & 9.7 & 8.1 & 10.1 & 7.1 & 6.7 \\
\hline $30-34$ & 7.3 & 7.9 & 7.8 & 7.1 & 8.1 & 7.5 & 8.4 & 7.3 & 6.9 \\
\hline $35-39$ & 7.1 & 7.1 & 7.9 & 6.7 & 7.1 & 8.0 & 7.3 & 7.5 & 7.3 \\
\hline $40-44$ & 6.0 & 6.1 & 7.5 & 5.8 & 6.1 & 7.8 & 6.2 & 8.6 & 8.9 \\
\hline $45-49$ & 5.2 & 5.3 & 6.5 & 5.6 & 5.3 & 7.1 & 5.3 & 7.8 & 8.5 \\
\hline $50-54$ & 4.1 & 4.3 & 5.1 & 4.7 & 4.3 & 5.6 & 4.2 & 6.7 & 7.2 \\
\hline $55-59$ & 3.2 & 3.6 & 4.3 & 4.3 & 3.6 & 4.8 & 3.5 & 5.7 & 6.0 \\
\hline $60-64$ & 3.1 & 3.1 & 3.6 & 3.8 & 3.1 & 3.6 & 3.0 & 3.4 & 3.5 \\
\hline $65-69$ & 2.2 & 2.2 & 2.2 & 2.8 & 2.2 & 2.5 & 2.1 & 2.4 & 2.5 \\
\hline 70-74 & 1.6 & 1.5 & 1.2 & 1.8 & 1.5 & 1.3 & 1.4 & 1.4 & 1.4 \\
\hline 75-79 & 0.8 & 0.9 & 0.6 & 0.9 & 0.9 & 0.6 & 0.9 & 0.9 & 0.9 \\
\hline $80+$ & 0.9 & 0.7 & 0.4 & 1.1 & 0.8 & 0.4 & 0.8 & 0.7 & 0.7 \\
\hline Total & 100 & 100 & 100 & 100 & 100 & 100 & 100 & 100 & 100 \\
\hline
\end{tabular}

Source: Appendix Table C-13, Census 2011, SRS Statistical Reports of respective years, International Institute for Population Sciences (2017), Table 2.12 and unit-level CPHS data from the September-December waves of respective years. 
Table 2: Sex-ratio (females per 1000 males) from Census, NFHS-4 and CPHS

\begin{tabular}{ccccc}
\hline \hline Age group & $\begin{array}{c}\text { Census } \\
\mathbf{2 0 1 1}\end{array}$ & $\begin{array}{c}\text { NFHS-4 } \\
\mathbf{2 0 1 5 - 1 6}\end{array}$ & $\begin{array}{c}\text { CPHS } \\
\text { Jan-Apr 2014 }\end{array}$ & $\begin{array}{c}\text { CPHS } \\
\text { Sep-Dec 2019 }\end{array}$ \\
\hline & \multicolumn{5}{c}{ Overall } & & \\
\hline All ages & 940 & 991 & 880 & 883 \\
0-6 years & 914 & 916 & 875 & 883 \\
\hline & \multicolumn{5}{c}{ Rural } & 871 \\
\hline All ages & 947 & 1009 & 868 & 877 \\
0-6 years & 919 & 923 & 870 & 909 \\
\hline & Urban & & 897 \\
\hline All ages & 926 & 956 & 906 & \\
$0-6$ years & 902 & 899 & 889 & \\
\hline \hline
\end{tabular}

Source: Office of the Registrar General \& Census Commissioner, India (2011), International Institute for Population Sciences (2017), Table 2.12 and unit-level CPHS data. 
Table 3a: Poverty indicators, 2015 and 2019 - NFHS versus CPHS

\begin{tabular}{|c|c|c|c|c|}
\hline \multirow{2}{*}{ Indicator } & \multicolumn{2}{|c|}{2015} & \multicolumn{2}{|c|}{$2019^{a}$} \\
\hline & NFHS-4 & CPHS & NFHS-5 & CPHS \\
\hline \multicolumn{5}{|c|}{ Illiterate adults (15-49-years, \%) } \\
\hline Women & 32 & 26 & 28 & 2 \\
\hline Men & 16 & 10 & 16 & 1 \\
\hline \multicolumn{5}{|c|}{ Households without access to (\%) } \\
\hline Electricity & 12 & 2 & 2 & 0.1 \\
\hline Water in the house ${ }^{b}$ & 33 & 7 & 23 & 6 \\
\hline Toilet $^{c}$ & 40 & 8 & 17 & 1 \\
\hline \multicolumn{5}{|c|}{ Households that do not own a (\%) } \\
\hline Television & 35 & 11 & 29 & 6 \\
\hline Fridge & 70 & 59 & 62 & 45 \\
\hline Air conditioner/cooler & 82 & 68 & 83 & 66 \\
\hline
\end{tabular}

$a$ - Population-weighted average of state-specific figures of the 11 major states for which NFHS-5 data is available (Andhra Pradesh, Assam, Bihar, Gujarat, Himachal Pradesh, Jammu and Kashmir, Karnataka, Kerala, Maharashtra, Telangana, and West Bengal). In the case of CPHS, state-specific estimates were calculated using state-level weights provided by CMIE.

$b$ - In the case of NFHS, refers to households that neither have water on premises nor get it delivered to their dwelling.

$c$ - In the case of CPHS, refers to households that do not have a toilet in their house. For NFHS, refers to households that do not have access to any toilet, including public toilets.

Source: Unit-record data of CPHS September-December waves of 2015 and 2019, International Institute for Population Sciences (2017), Tables 2.1, 2.2, 2.8, 3.3.1 and 3.3.2, and International Institute for Population Sciences (2021), State Reports, Tables 4, 5, 7, and 17. 
Table 3b: Comparable poverty indicators in recent national surveys

\begin{tabular}{lcccc}
\hline \hline Indicator & $\begin{array}{c}\text { NFHS-5 } \\
\mathbf{2 0 1 9 - 2 0}\end{array}$ & $\begin{array}{c}\text { CSDS NES } \\
\mathbf{2 0 1 9}\end{array}$ & $\begin{array}{c}\text { CSDS SES } \\
\mathbf{2 0 1 7 - 2 1}\end{array}$ & $\begin{array}{c}\text { CPHS } \\
\mathbf{2 0 1 9}\end{array}$ \\
\hline Households without a (\%) & & & & \\
$\quad$ Television & 29 & 26 & 23 & 6 \\
$\quad$ Toilet $^{a}$ & 17 & 29 & 31 & 1 \\
Fridge & 62 & 61 & 59 & 45 \\
\hline \hline
\end{tabular}

$a$ - Lokniti-CSDS surveys and CPHS record whether sample households have a toilet in their house while NFHS records whether sample households have access to any toilet, including public toilets.

Source: International Institute for Population Sciences (2021), State Reports, Tables 5 and 7, unitlevel CPHS data, and personal communication with Sanjay Kumar and Shreyas Sardesai at Lokniti-CSDS. Figures are population-weighted averages of state-specific figures for 11 major states (see Table 3a notes), for which NFHS-5 data are available; they apply to September-December 2019 for CPHS, 2019-20 for NFHS-5, and April-May 2019 for Lokniti-CSDS NES 2019. In the case of Lokniti-CSDS SES, the reference period corresponds to the timing of the respective state assembly elections, starting with Himachal Pradesh in November 2017 and ending with West Bengal and Kerala in March and April 2021. Since SES were not carried out in Jammu and Kashmir and Maharashtra, NES figures are used instead. In the case of CPHS data, state-specific estimates for the 11 major states were calculated, using the state-level weights, and then averaged using state population as weights. 
Table 4: Decile-specific real mean consumption expenditure in 2017-18

\begin{tabular}{cccccccc}
\hline \hline \multirow{2}{*}{ Decile } & \multicolumn{3}{c}{ Rural } & & \multicolumn{3}{c}{ Urban } \\
\cline { 2 - 5 } \cline { 7 - 8 } \cline { 6 - 8 } & PLFS & CES & CPHS & & PLFS & CES & CPHS \\
\hline 1 & 548 & 721 & 710 & & 796 & 1079 & 944 \\
2 & 761 & 915 & 1011 & & 1157 & 1514 & 1352 \\
3 & 917 & 1069 & 1206 & & 1424 & 1821 & 1638 \\
4 & 1029 & 1203 & 1389 & & 1725 & 2121 & 1912 \\
5 & 1172 & 1329 & 1583 & & 1973 & 2443 & 2201 \\
6 & 1327 & 1471 & 1799 & & 2327 & 2812 & 2531 \\
7 & 1503 & 1644 & 2059 & & 2750 & 3245 & 2931 \\
8 & 1766 & 1870 & 2401 & & 3426 & 3860 & 3478 \\
9 & 2141 & 2223 & 2944 & & 4436 & 4783 & 4363 \\
10 & 3469 & 3578 & 4761 & & 7865 & 8478 & 7385 \\
\hline Overall mean & $\mathbf{1 4 6 1}$ & $\mathbf{1 5 9 6}$ & $\mathbf{2 0 0 1}$ & $\mathbf{2 7 7 7}$ & $\mathbf{3 2 1 5}$ & $\mathbf{2 9 0 6}$ \\
\hline \hline
\end{tabular}

Note: Figures are in constant January 2017 prices.

Source: PLFS estimates were calculated from 2017-18 unit-level data. CES estimates, in 2011-12 prices, were sourced from Subramanian (2019b), Table 2. They were first re-estimated in 2012 prices using RBI's rural and urban series of the new CPI and then re-estimated in January 2017 prices using the CPI General Index (Base year $2012=100$ ). To arrive at CPHS estimates, the following steps were followed: (i) From the full set of monthly household observations between January 2017 to December 2018, only those observations were retained where the reference month immediately preceded the survey month, leaving us with essentially 6 'waves' of consumption data spanning the 24-month period. (ii) Total household expenditure was divided by the household size to arrive at per-capita consumption expenditure which was assigned to each household member and decile-specific means for the full sample of individuals was calculated using member-level weights. (iii) Steps (i) and (ii) were repeated for each of the 6 waves and then the decile-specific values averaged using the number of respondents per decile per wave as the weight. Money expenditures from PLFS and CPHS were deflated using the monthly rural and urban series of the CPI General Index (Base year $2012=100$ ). 
Table 5: Labour incomes, 2018-19 - PLFS versus CPHS

\begin{tabular}{cccccc}
\hline \hline & \multicolumn{2}{c}{ Rural } & & \multicolumn{2}{c}{ Urban } \\
\cline { 2 - 3 } \cline { 5 - 6 } \cline { 5 - 6 } & PLFS & CPHS & & PLFS & CPHS \\
\hline $10^{\text {th }}$ percentile & 2630 & 0 & & 4345 & 0 \\
$25^{\text {th }}$ percentile & 4304 & 4551 & & 7352 & 8953 \\
$50^{\text {th }}$ percentile & 6986 & 8971 & & 11237 & 14562 \\
$75^{\text {th }}$ percentile & 10035 & 14061 & & 20065 & 23644 \\
$90^{\text {th }}$ percentile & 15178 & 24895 & & 35262 & 41848 \\
$95^{\text {th }}$ percentile & 20238 & 37635 & & 47762 & 53134 \\
\hline Overall mean & $\mathbf{8 4 1 3}$ & $\mathbf{1 2 2 8 6}$ & & $\mathbf{1 7 0 2 1}$ & $\mathbf{1 9 2 0 7}$ \\
\hline \hline
\end{tabular}

Source: Appendix Table 13, State of Working India 2021 report (Azim Premji University, 2021). See also Box 4.2 in the report. 
Figure 1: Population pyramid - SRS 2018 versus CPHS 2019

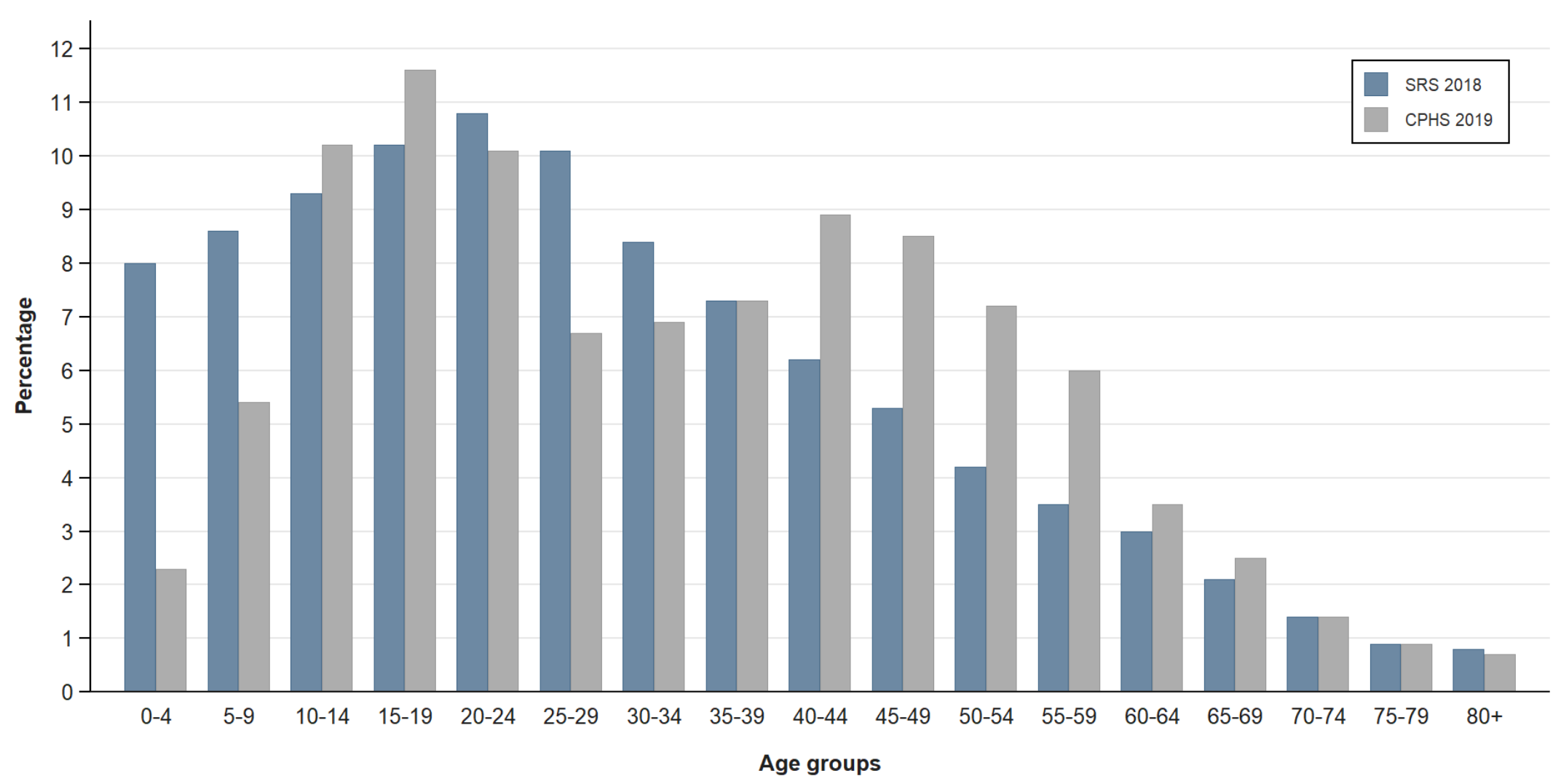

Source: SRS 2018 Statistical Report and September-December 2019 CPHS unit-level data. 
Figure 2: Adult literacy rates in the CPHS sample, 2014-2020

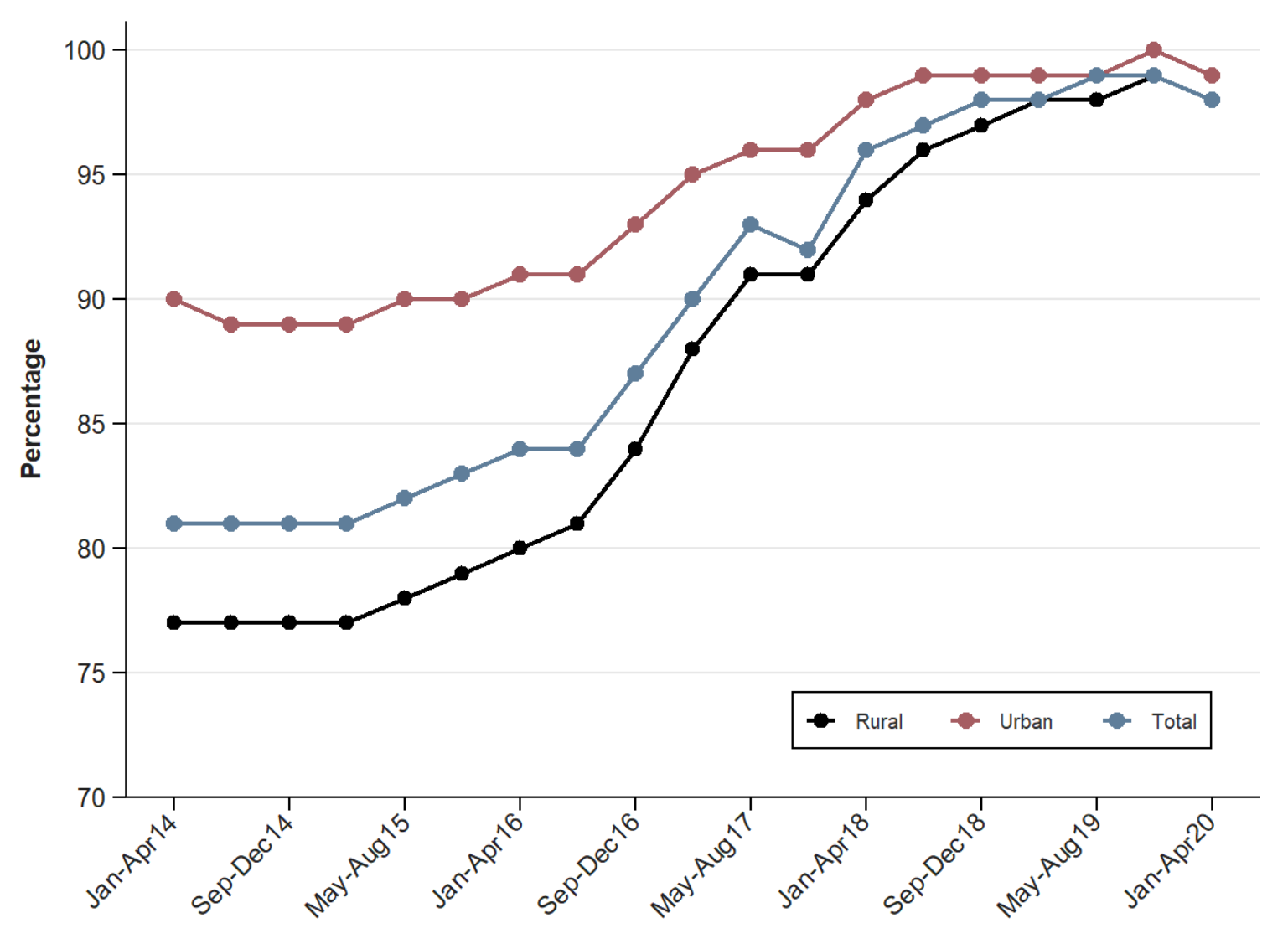

Source: Calculated from successive waves of CPHS unit-level data. Figures relate to 15-49-year-olds. 
Figure 3: Female illiteracy rates, 2019 - CPHS versus NFHS-5

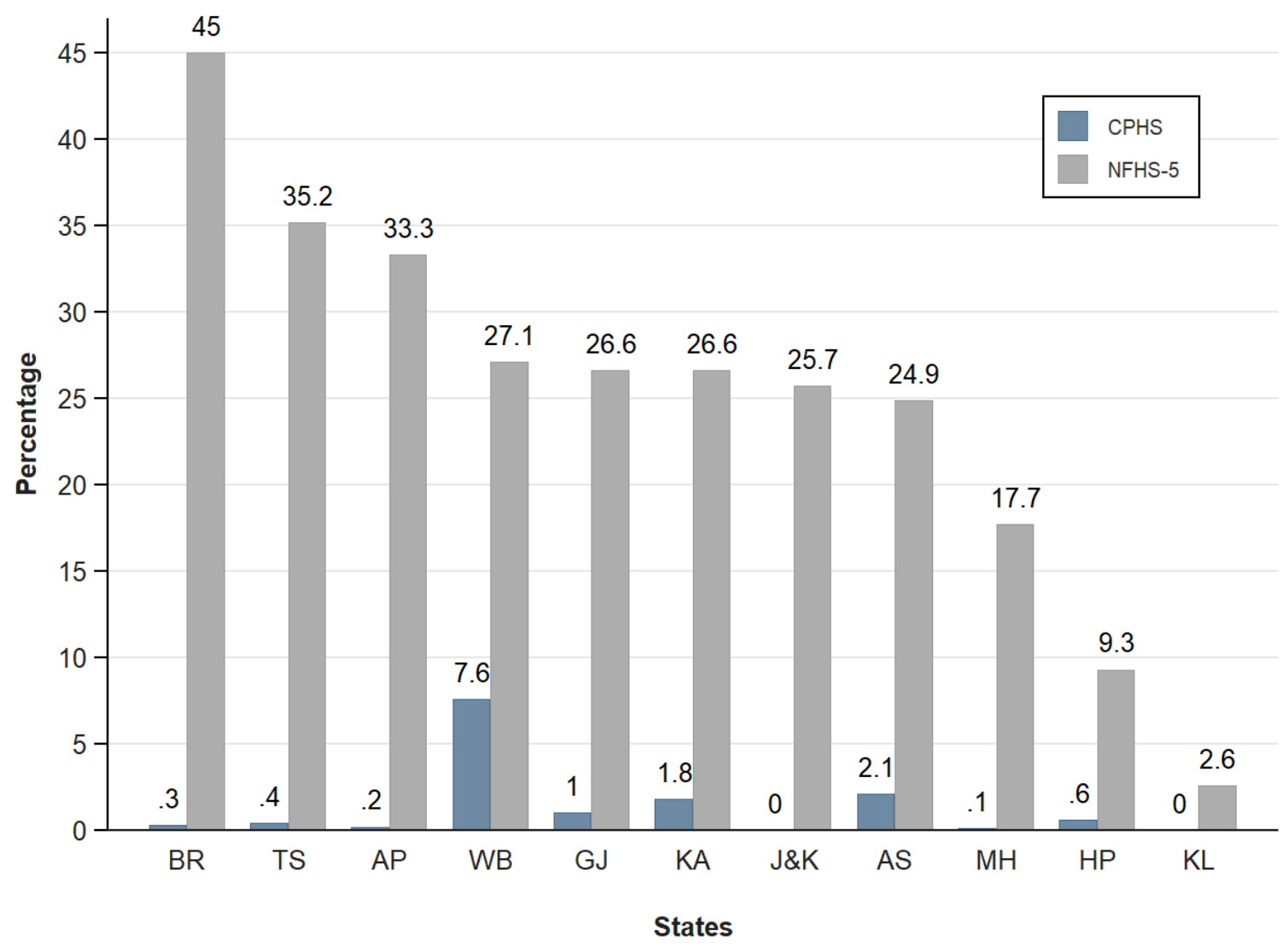

Source: Unit-level CPHS data and International Institute for Population Sciences (2021). Figures relate to 15-49-year-olds and apply to 2019-20 for NFHS-5 and September-December 2019 for CPHS. 
Figure 4: Share of adults with no formal education, 2014-18 - CPHS versus FII

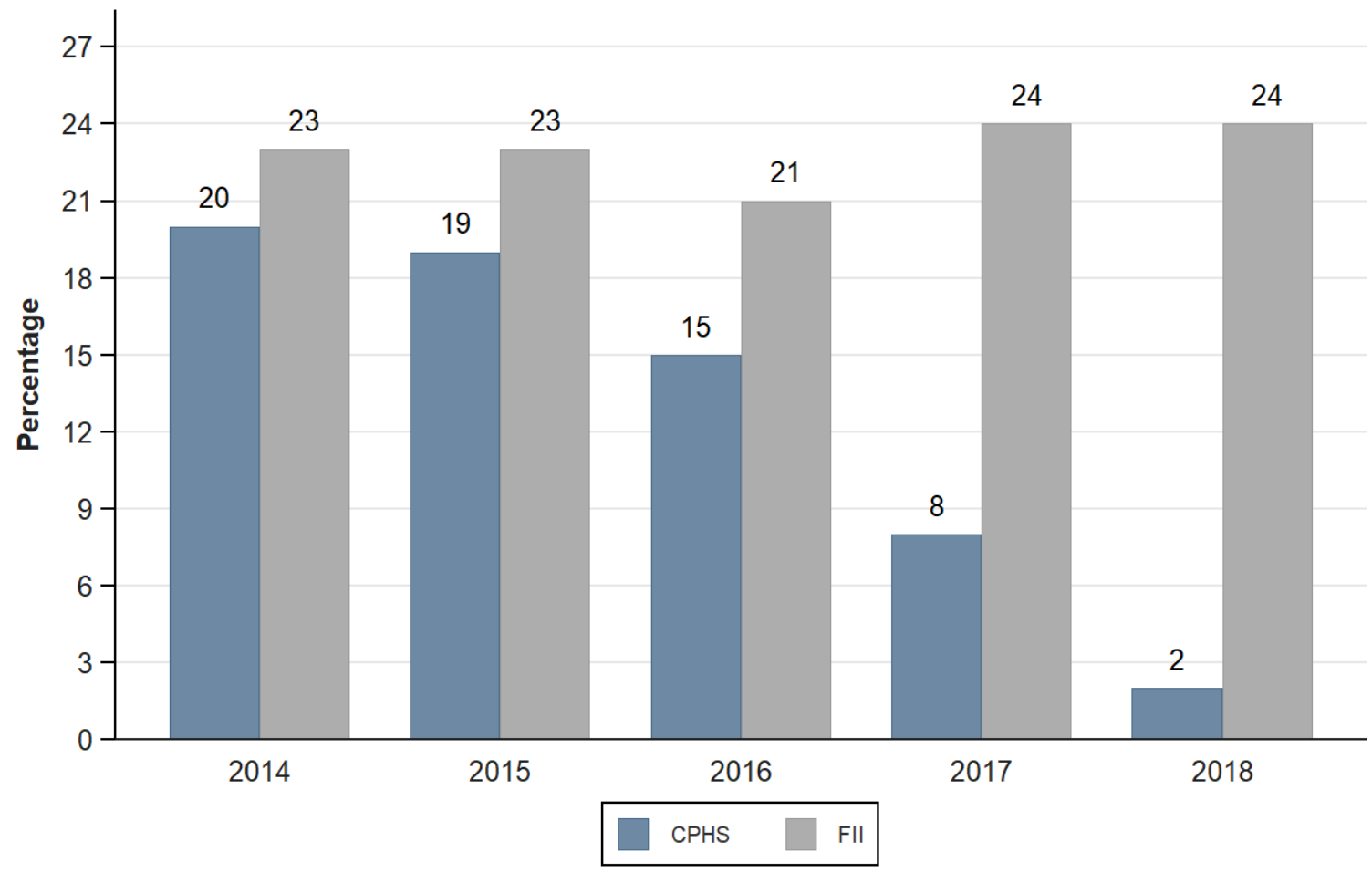

Source: Unit-level CPHS (September-December waves) and FII data. Figures apply to 15-49-year-olds. 
Figure 5: Household-level per-capita consumption expenditure in CPHS, 2016-2020

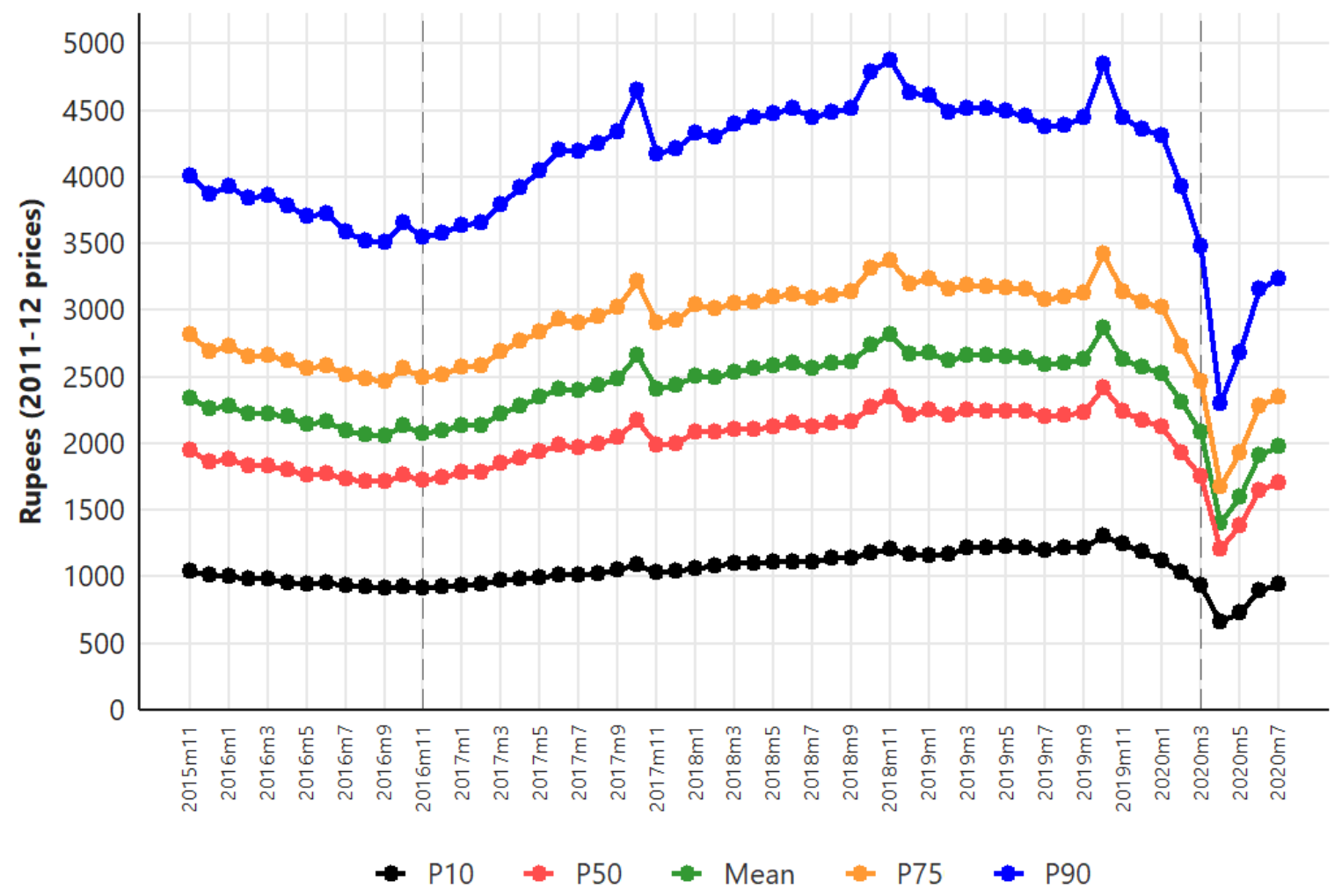

Source: Unit-level CPHS data. Money expenditures in current prices were deflated using the monthly series of the Consumer Price Index (CPI, Combined General Index). P10, P50, P75, and P90 present the deflated rupee value of the $10^{\text {th }}, 50^{\text {th }}, 75^{\text {th }}$ and $90^{\text {th }}$ percentile of the household-level distribution in each month. The dashed vertical lines represent the months when demonetization (November 2016) and the national lockdown (March 2020) were announced. 